\title{
Study of $\mathrm{TiO}_{2} \mathrm{NWs-based} \mathrm{FET} \mathrm{immunosensor:} \mathrm{effect} \mathrm{of}$ surface immobilization methods
}

\author{
Chi-Chang Lin ${ }^{1 *}$, Yung-Ming Chü ${ }^{2}$, Hsien-Chang Chang ${ }^{2 *}$ \\ ${ }^{1}$ Dept. Chem\& Matls Eng., Tunghai University, No 181, Sec 3, Taichung port Rd., Taichung, Taiwan; \\ ${ }^{2}$ Inst. Biomed. Eng., National Cheng Kung University, No 1, University Rd., Tainan, Taiwan \\ Corresponding e-mail: chichang31@thu.edu.tw; hcchang@mail.ncku.edu.tw
}

\begin{abstract}
Immobilization of biomolecule on biosensor surface is an important issue for develop higher sensitivity immunosensors. Recognition elements can be modified on material surface through chemical conjugate, physical adsorption and, polymer entrapment etc. Although most of these methods are well established, none of them can perform both in situ immobilization of biomolecues and be easily established. In this study, anti-rabbit $\operatorname{lgG}\left(1^{\circ} \mathrm{Ab}\right)$ is encapsulated by a cyclic-voltammetry for

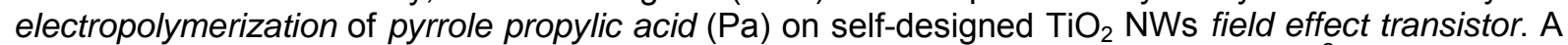
better specificity, selectivity and sensitivity can be achieved at nano-gram level $\left(R^{2}=0.903\right)$ when compared with 3-aminopropyltrimethoxysilane (APTMS).
\end{abstract}

Key words: in situ immobilization, electropolymerization, pyrrole propylic acid, field effect transistor

\section{Introductions}

Over the past decade, field effect transistors (FETs) constructed by one-dimensional (1-D) nanomaterial have been widely introduced to biosensing research and applications owing to its high sensitivity and specificity properties. Most important part of all nanostructure-based materials for biosensors is their ability of specific antibody recoganetions. Many chemical- and physical-based methods, such as silane linking or polymer entrapment, are well-established protocols for immobilizing biomolecules on matrices [1-3] and related technologies have become the standard method [4]. Unfortunately, device sensitivity may decrease when non target area is polluted via physical adsorptions of proteins. In this research, we compared two methods for encapsulation of biomolecules on biosensors using 3-aminopropyltrimethoxysilane (APTMS) and polypyrrole propylic acid $(\mathrm{Pa})$. Electrochemical polymerization of a lowconductivity polymer $\mathrm{Pa}(\mathrm{PPa})$ [1] for the encapsulation of biomolecules on $\mathrm{TiO}_{2}-$ nanowire (NW) FET immunosensor is discussed. The electrical analysis and the energy dispersive spectrum were recorded for investigation of $\mathrm{PPa}$ and $1{ }^{\circ} \mathrm{Ab}$ on a composite film. The specificity, selectivity and sensitivity of the biosensor were analyzed in order to determine the immunoreaction of $\mathrm{PPa} / 1^{\circ} \mathrm{Ab}$ immobilized $\mathrm{TiO}_{2}$-NW FET immunosensors.

\section{Materials and Methods}

$\mathrm{TiO}_{2} \mathrm{NWs}$ was made of simple hydrothermal synthesis method followed by spin-coated on the gold microelectrode with designed gap of 1 $\mu \mathrm{m}$ [4]. Mixture solution contains $15 \mathrm{mM}$ of polypyrrole propylic acid $(\mathrm{Pa})$ (supported by $\mathrm{C}$. M. Li [1]) and $100 \mu \mathrm{g} / \mathrm{mL}$ primary antibody (Antirabbit IgG, $1^{\circ} \mathrm{Ab}$ ) was added into $1 \mathrm{~mL}$ of 10 $\mathrm{mM}$ phosphate buffered saline (PBS) solution and then electrochemical polymerized to form a composite film on patterned NWs. Electrochemical polymerization was performed by using cyclic voltammetry method at a voltage ranging from 0 to $0.76 \mathrm{~V}$ vs. $\mathrm{Ag} / \mathrm{AgCl}$ for 20 cycles, scan rate of $0.1 \mathrm{~V} / \mathrm{sec}$, and with a $\mathrm{Pt}$ counter electrode [1].

Characterization of antibody immobilized- $\mathrm{TiO}_{2}$ NWs immunosensor shows good affinity for rabbit lgG (secondary antibody, $2^{\circ} \mathrm{Ab}$ ) detection which performed on our designed device. The surface properties changes on the designed immunosensor during the preparation processes of $\mathrm{NWs}, \mathrm{PPa}\left(\mathrm{PPa} / \mathrm{TiO}_{2} \mathrm{NWs}\right)$, antirabbit IgG $\left(1^{\circ} \mathrm{Ab} / \mathrm{PPa} / \mathrm{TiO}_{2} \mathrm{NWs}\right.$ immunosensor $)$, and the specific adsorption of rabbit $\lg G\left(2^{\circ} \mathrm{Ab}-\right.$ $1^{\circ} \mathrm{Ab} / \mathrm{PPa} / \mathrm{TiO}_{2} \quad \mathrm{NWs}$ immunosensor) were recorded and expressed by the changes of current-voltage. 


\section{Results and Discussions}

Diameters of prepared $\mathrm{TiO}_{2} \mathrm{NWs}$ are calculated around $250 \mathrm{~nm}$ to $400 \mathrm{~nm}$ from SEM image, as showed in Figure 1.

Synthesis $\mathrm{TiO}_{2} \mathrm{NW}$ presents anatase structure as three characteristic peaks stand at 395,514 and $638 \mathrm{~cm}^{-1}$ analyzed under Raman spectroscopy with $532 \mathrm{~nm}$ laser (see Fig.2). Mixture contains synthesis NWs was then spincoated on the $\mathrm{Au} / \mathrm{Ti}$ microelectrodes with the designed gap of $1 \mu \mathrm{m}$.

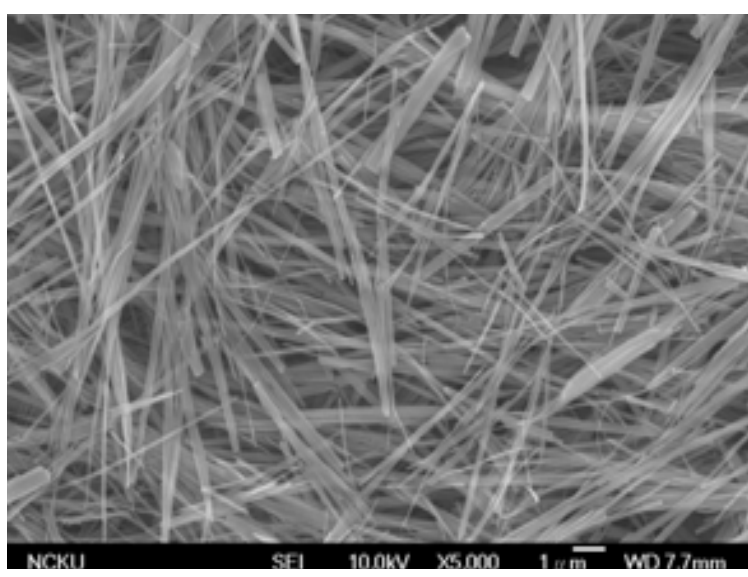

Fig. 1. SEM image of $\mathrm{TiO}_{2} \mathrm{NWS}$ on designed electrode

Experiment setup of the electrochemical polymerization system and the structure of conduction polymer (pyrrole propylic acid) before and after polymerization were showed in Fig. 3(a). Cyclic voltametry was applied for in situ electrochemical polymerization of pa-co-1 ${ }^{\circ} \mathrm{Ab}\left(100 \mu \mathrm{g} / \mathrm{mL}\right.$ of $1^{\circ} \mathrm{Ab}$ with $15 \mathrm{mM} \mathrm{Pa}$ in a 10 $\mathrm{mM}$ PBS) on the surface of NWs. Operation conditions for cyclic voltammetry was set at $0 \sim 0.76 \mathrm{~V}$ with scan rate $0.1 \mathrm{~V} / \mathrm{sec}$ for 20 cycles. As illustrated in the inset figures, antibody can be encapsulated around the surface of NWs during the polymerization process in which $\mathrm{PPa}$ was polymerized from $\mathrm{Pa}$ monomer.

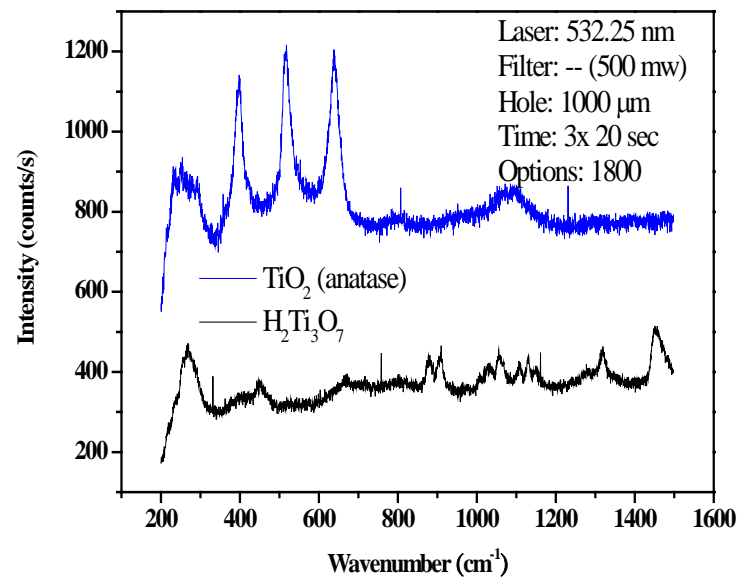

Fig. 2. Raman spectra of prepared $\mathrm{TiO}_{2} \quad \mathrm{NW}$. Anatase structure can be characterized by identified peaks at 395, 514 and $638 \mathrm{~cm}^{-1}$.

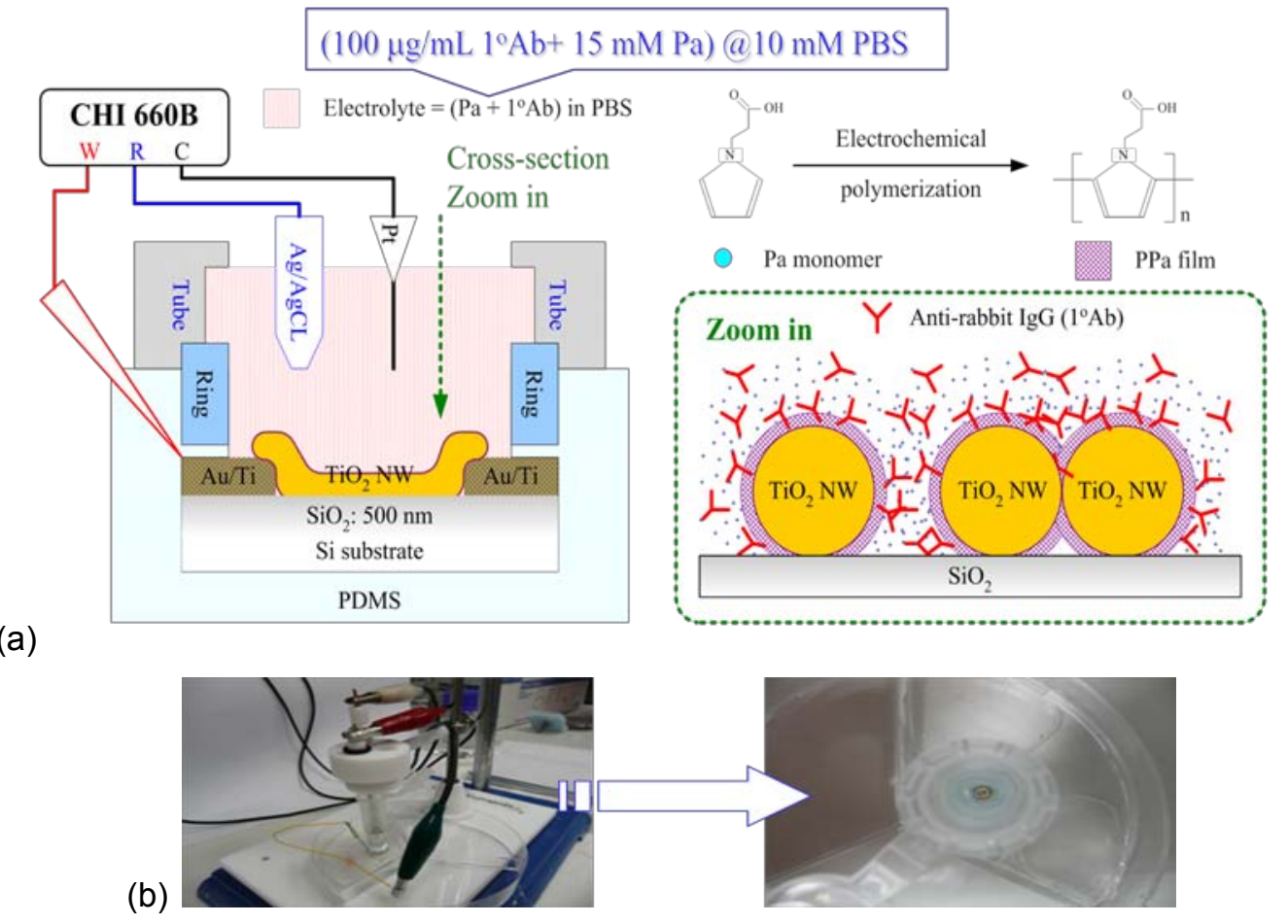

Fig. 3. Schematic diagram (a) and photos(b) of electrochemical polymerization system setup. Mixture of electrolytes was prepared by adding $100 \mu \mathrm{g} / \mathrm{mL}$ of $1^{\circ} \mathrm{Ab}$ with $15 \mathrm{mM}$ Pa in a $10 \mathrm{mM}$ PBS. Operation conditions for cyclic voltammetry was set at 0 0.76 V with scan rate $0.1 \mathrm{~V} / \mathrm{sec}$ for 20 cycles. Antibody can be encapsulated around the surface of NWs during the polymerization process which PPa was polymerized from Pa monomer. 
The target biomolecules can be entrapped via electrochemical polymerization of $\mathrm{PPa}$ on the designed $\mathrm{TiO}_{2} \mathrm{NWs}$ immunosensor while the APTMS group was stand-coated on the whole area of the device surface. Figure 4 indicated the result of DES analysis on NWs surface. Here blue and red color represent the distribution of $\mathrm{Ti}$ and $\mathrm{C}$ elements, respectively.

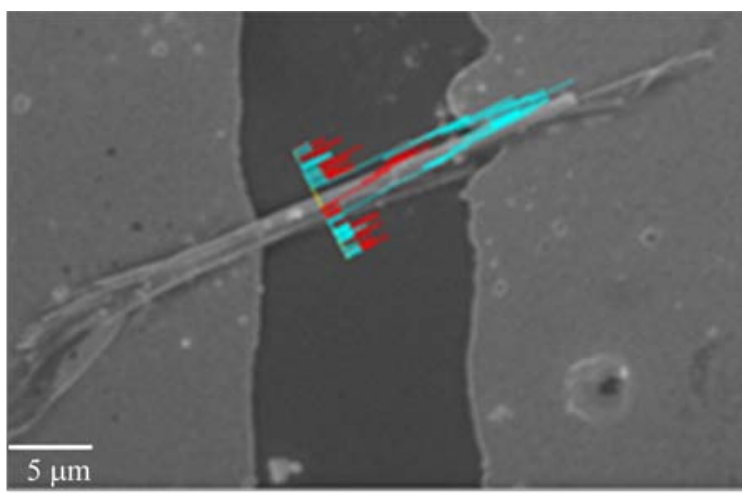

Fig. 4. DES analysis of NWs. Blue and red color represent the element contents of $\mathrm{Ti}$ and $\mathrm{C}$, respectively.

Measured current changed before and after polymerization, and after affinity reacted with $11.9 \mathrm{ng} / \mathrm{mL}$ of $2^{\circ} \mathrm{Ab}\left(\mathrm{V}_{\mathrm{DS}}=5 \mathrm{~V}\right)$, as response curves showed in Fig. 5(a) and 5(b). As can be seen clearly, when polymerization mixture contains no $1^{\circ} \mathrm{Ab}$, there are no current changes when target $2^{\circ} \mathrm{Ab}$ was added.

Response curve of $\mathrm{I}_{\mathrm{D}}-2^{\circ} \mathrm{Ab}$ concentration presents linear decrease tendency with the increase of target $2^{\circ} \mathrm{Ab}$ concentration (Fig. 6). In contrast, immunoresponse of polymerized PPabased $\mathrm{TiO}_{2}-\mathrm{NW}$-immunosensor group showed a better sensitivity with linear region $\left(\mathrm{V}_{\mathrm{DS}}=5 \mathrm{~V}\right)$ at $2^{\circ} \mathrm{Ab}$ concentrations lower than $5.95 \mathrm{ng} / \mathrm{mL}$ when compared with APTMS modified group (Fig. 6a). Below two schematics illustrated the surface modification difference between $\mathrm{PPa}$ and APTMS on the $\mathrm{TiO}_{2}$ NWs-based immunosensor device.

Our results shows higher similarity to that of previous literatures, the cross section of depletion region, near the $\mathrm{TiO}_{2}$ NWs surface might be increased while the concentration of adsorbed target $2^{\circ} \mathrm{Ab}$ increased; otherwise the current flow in the back of substrate was decreased significantly under bias-free status.

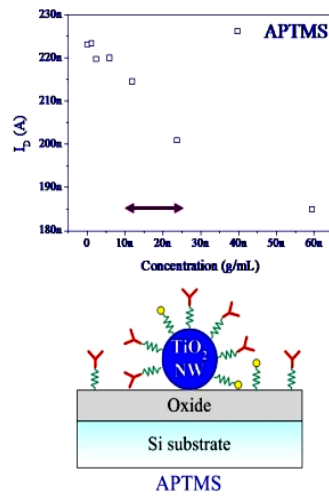

(a)

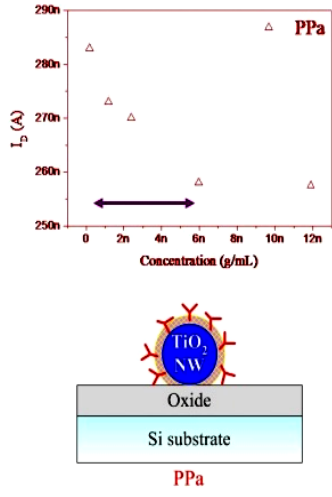

(b)
Fig. 6. Response curve of $I_{D}$ under various concentrations of $2^{\circ} \mathrm{Ab}$ and the schematic diagrams of two different modification methods. Biomolecule immobilized by APTMS (a)and via PPa (b). (a)

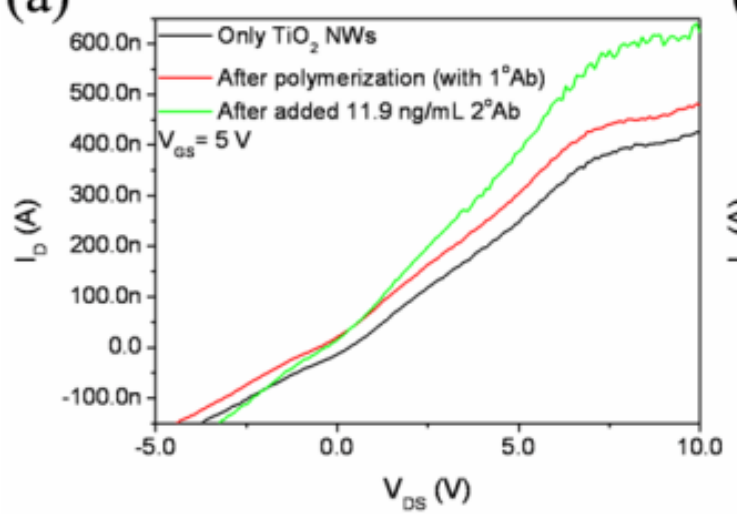

$2^{\circ} \mathrm{Ab}$

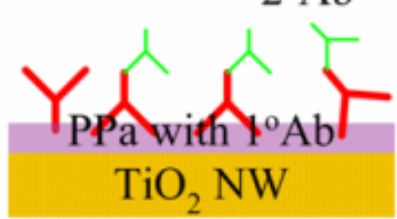

(b)

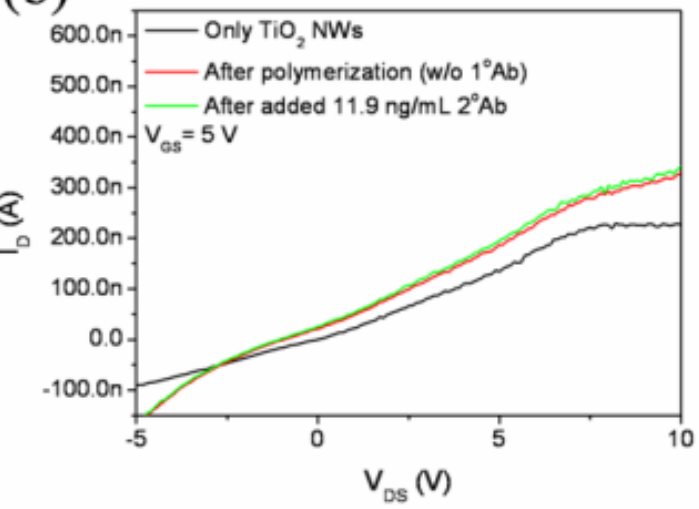

$2^{\circ} \mathrm{Ab}$

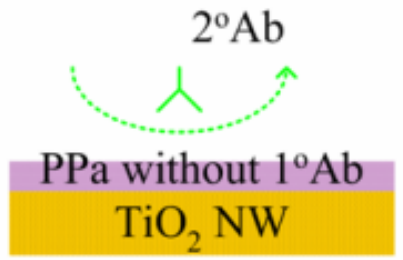

Fig. 5. Measured current changed before and after polymerization, and after affinity reacted with $11.9 \mathrm{ng} / \mathrm{mL}$ of $2^{\circ} \mathrm{Ab}\left(V_{D S}=5 \mathrm{~V}\right)$. Biomolecule immobilized by APTMS (a)and via PPa (b). 


\section{Conclusion}

Encapsulation of biomolecules via the electropolymerization of low conductivity $\mathrm{PPa}$ on $\mathrm{TiO}_{2} \mathrm{NWs}$ immunosensor achieves a better sensitivity than that of using APTMS. Detection limitation of the target rabbit IgG can as lower as to nano-gram level $\left(R^{2}=0.903\right)$.

\section{Acknowledgements}

Authors would like to thanks Prof. C.M. Li at NTU, Singarpore for supportting pa monomer. This study is financed by the Landmark Project (D97-2700) of National Cheng Kung University, and National Science Council of the Republic of China (NSC 99-2218-E-029-004).

\section{References}

[1] H. Dong, C. M. Li, W. Chen, Q. Zhou,Z.X. Zeng, J.H.T. Luong, Analytical Chemistry 78(21), 74247431 (2006); doi: 10.1021/ac060657o

[2] J. Wang, M. Musameh, Analytica Chimica Acta, 539 (1-2), 209-213 (2005); doi:10.1016/j.aca.2005.02.059

[3] H. Tang, J. H. Chen, S. Z. Yao, L. H. Nie, G. H. Deng, Y. F. Kuang, Analytical Biochemistry 331 (1), 89-97 (2004); doi:10.1016/j.ab.2004.05.005

[4] Y. M. Chu, C.C. Lin, H.C. Chang, C.M. Li, Biosensors and Bioelectronics 26(5), 2334-2340 (2010); doi:10.1016/j.bios.2010.10.006 